\title{
Magnetic and Resonance Study of Double doped M-type hexaferrite $\mathrm{Ba}_{1-\mathrm{x}}\left(\mathrm{Cu}_{\mathrm{x}} \mathrm{Al}_{\mathrm{x}} \mathrm{Fe}_{12-\mathrm{x}}\right) \mathrm{O}_{19}$
}

\author{
T. Ravindra Reddy ${ }^{1}$, P. Narayana Reddy ${ }^{2}$, S. Lakshmi Reddy ${ }^{3}$, Yoshinobu Nakamura ${ }^{4}$, \\ Satoru Kaneko ${ }^{5}$, Paolo Mele ${ }^{6}$, Taras Polek ${ }^{7}$, Tamio Endo ${ }^{8}$
}

${ }^{1}$ Department of Physics, AITS, Cuddapah 516003, India

${ }^{2}$ Department of Physics, Government College for Men, Cuddapah 516001, India

${ }^{3}$ Department of Physics, SV Degree College, Cuddapah 516003, India

${ }^{4}$ The University of Tokyo, 7 Chome-3-1 Hongo, Bunkyo, Tokyo, Japan

${ }^{5}$ Kanagawa Institute of Industrial Science and Technology, Shimo-Imaizumi, Ebina, Kanagawa 2430435, Japan

${ }^{6}$ Shibaura Institute of Technology, Toyosu Campus, SIT Research Laboritiries, 3-7-5 Toyosu, Koto-ku 4th Floor, Tokyo 1358548, Japan

${ }^{7}$ Institute of Magnetism of the NAS of Ukraine and MES of Ukraine, 36b Vernadsky Avenu, Kyiv 03142, Ukraine

${ }^{8}$ Japan Advanced Chemicals, 3007-4 Kamiechi, Atsugi, Kanagawa, Kanagawa 2430801, Japan

*Corresponding Author. Email: drslreddy_in@yahoo.com

Received: 28 August 2019, Accepted: 30 September 2019, Published Online: 02 October 2019

Citation Information: T. Ravindra Reddy, P. Narayana Reddy, S. Lakshmi Reddy, Yoshinobu Nakamura, Satoru Kaneko, Paolo Mele, Taras Polek, Tamio Endo. Frontier Research Today 2019;2:2007. doi: 10.31716/frt.201902007 Cite in Other Styles

ABSTRACT: Nanoparticles of $\mathrm{Ba}_{1-\mathrm{x}}\left(\mathrm{Al}_{\mathrm{x}} \mathrm{Cu}_{\mathrm{x}} \mathrm{Fe}_{12-\mathrm{x}}\right) \mathrm{O}_{19}$ ( $\mathrm{x}$ varies from $\mathrm{O}$ to 1 ) were prepared by solid-state reaction route method. The structural and morphological characterization of samples has been investigated by $X$-ray diffraction and TEM. Electron Spin Resonance (ESR), Mossbauer, VSM techniques were used to study the magnetic properties of the compounds. Change in the magnetic state of nanoparticles due to doping was also examined. Mossbauer studies suggest that the sample is ferrimagnetic when $x$ equals 0 and completely paramagnetic when $x$ euqals 1 . ESR studies reveal splitting of resonance lines at certain concentrations (x) of $\mathrm{Cu} / \mathrm{Al}$. VSM and ESR studies reveal the destruction of collective magnetism when doping is increased.

Keywords: Doped barium ferrite; Eelectron spin resonance; Mossbauer spectroscopy; Magnetic properties

\section{INTRODUCTION}

Hexagonal ferrites are one of the most important materials for modern industrial world. These materials have been employed in the manufacture of simple permanent magnets, data storage and microwave devices ${ }^{1}$. Ba - hexaferrite, also known as M-type $\left[(\mathrm{Ba}, \mathrm{Sr}) \mathrm{Fe}_{12} \mathrm{O}_{19}\right]$, has attracted particular attention because of its significant properties like magnetic magnetocrystalline anisotropy, high coercive field, and Curie temperature ${ }^{2}$. Being M-type hexaferrite, it has a complex structure where $\mathrm{Fe}^{3+}$ ions have nonequivalent positions and are separated by $\mathrm{O}^{2-}$ ions. The spins of opposing iron ions are linked by interactions which take place via the intermediate oxygen atom, and this is termed as super-exchange ${ }^{1}$. In general, the magnitude of exchange depends on distance in Metal-Oxygen-Metal chain angle. The smallest interaction occurs at $90^{\circ}$ and maximum exchange takes place at $180^{\circ}$. So the distortions in iron environments (oxygen polyhedrons) result in super-exchange and hence consequently change the magnetic properties. Thus the behavior of hexaferrites is similar to substituted manganites where magnetic ions of manganese interact with each other by double exchange . $^{3}$.

Doping is an effective method to change properties. $\mathrm{Ba}^{2+}(1.34 \AA)$ and $\mathrm{Fe}^{3+}(0.64 \AA)$ ions have different ionic radii. Accordingly, substitutions in different positions cause a different response. Also, $\mathrm{Fe}^{3+}$ ions of barium hexaferrites are distributed over five different sub-lattices ${ }^{1}$. There are many reports on substituted barium hexaferrites by different elements with different oxidation states and ionic radii $^{4-10}$. In a number of studies, it is observed that the substitution of $\mathrm{Al}^{3+}$ in the $\mathrm{Fe}^{3+}$-site leads to an increase in coercive force $\left(H_{\mathrm{C}}\right)^{4,11,12}$ and change in magnetic properties. Aluminum ions replace the iron ions and reduce the volume of the unit cell since ionic radius of $\mathrm{Al}^{3+}(0.54 \AA)$ is less than that of $\mathrm{Fe}^{3+}(0.64 \AA)$. This leads to a distortion of the oxygen polyhedrons and as a consequence, the super-exchange interaction is affected. The partial substitution of $\mathrm{Fe}^{3+}$ by $\mathrm{Al}^{3+}$ in barium hexaferrite has been studied by varying the concentration of $\mathrm{x}(0 \leq \mathrm{x} \leq 4)^{12}$. These results suggest that saturation magnetization $\left(M_{\mathrm{S}}\right)$ reduces and similarly coercive field growth increases with increase of aluminum concentration. Similar, results are also reported by others ${ }^{13}$. The increase of $H_{\mathrm{C}}$ was established when concentration of $\mathrm{Al}$ is increased from $2.8 \mathrm{kOe}$ at $\mathrm{x}=$ 0 to $4.7 \mathrm{kOe}$ at $\mathrm{x}=2$. The change of magnetic properties with small and equal amount of either $\mathrm{Al}$ or In in Ba ferrite has been studied ${ }^{4}$. These studies reveal that $H_{\mathrm{C}}$ is 14 times greater in indium doped ferrite than that in $\mathrm{Al}$ doped $\mathrm{Ba}$ ferrite. Further the total magnetic moment of samples is reduced from $20 \mu_{\mathrm{B}}$ (for pure Ba ferrite) to 19 and $16.7 \mu_{\mathrm{B}}$ for $\mathrm{Al}$ and In doped $\mathrm{Ba}$ ferrites. The authors reported that in In doped sample, distortion occurs in crystal structure due to the replacement of iron by indium ions $\left(\operatorname{In}^{3+}=0.79\right.$ $\AA)^{4}$ which have greater ionic radii thus creating frustrated magnetic structure in the sample.

Copper doped hexagonal barium ferrite $\left[\mathrm{BaFe}_{12-\mathrm{x}} \mathrm{Cu}_{\mathrm{x}} \mathrm{O}_{19}\right]$ was examined $^{14}$. Magnetic properties were investigated and found that when $\mathrm{x}=0.03$, the low coercive change $(\approx 0.64$ $\%)$ and saturation magnetization increase sharply ${ }^{15}$. Further increase of $\mathrm{Cu}$ doping increases saturation magnetization, Curie temperature and coercivity. Hexaferrite properties are sensitive to the method adopted in the synthesis ${ }^{1}$. Since Ba ion has large ionic radius, doping by ion having more ionic radius $(\approx 1 \AA)$ such as $\mathrm{Ce}^{3+}, \mathrm{Pr}^{3+}, \mathrm{La}^{3+}$ etc. ${ }^{6,16,17}$ can replace 
$\mathrm{Ba}$ in hexaferrite. Double doping in hexaferrite causes unexpected structural and magnetic properties ${ }^{5,6,18,19}$. So far, dual substitution of ions with large and small ionic radii of $\mathrm{Al}$ and $\mathrm{Cu}$ ions in hexaferrite was not reported. Therefore, we propose to synthesize $\mathrm{Ba}_{1-\mathrm{x}}\left(\mathrm{Cu}_{\mathrm{x}} \mathrm{Al}_{\mathrm{x}} \mathrm{Fe}_{12-\mathrm{x}}\right) \mathrm{O}_{19}$ ferrite via solid state route method by varying $\mathrm{x}$ from 0.00 to 1.00 in steps of 0.25 to study the influence of concentration of $\mathrm{Cu}$ / $\mathrm{Al}$ on the magnetic properties of the compound.

\section{EXPERIMENTAL}

Barium hexagonal ferrite $\mathrm{Ba}_{1-\mathrm{x}}\left(\mathrm{Cu}_{\mathrm{x}} \mathrm{Al}_{\mathrm{x}} \mathrm{Fe}_{12-\mathrm{x}}\right) \mathrm{O}_{19}(\mathrm{x}=0.0$, $0.25,0.5,0.75,1.0)$ samples were synthesized by employing solid state route method. Generally in synthetic ferrite systems, $\mathrm{Ba}$ composition remains constant and is at its regular lattice site while $\mathrm{Fe}$ has been replaced by $\mathrm{Cu} / \mathrm{Al}$. But in the present synthesis, compositions of $\mathrm{Ba}, \mathrm{Cu}, \mathrm{Al}$ and $\mathrm{Fe}$ are varied.

$\mathrm{X}$-ray diffractometry was performed by Philips X-ray diffractometer using $\mathrm{Cu}-\mathrm{K}_{\alpha}$ radiation $(\lambda=1.54060 \AA$ ) at room temperature. Information about morphology and particle size were obtained on Philips CM 200 transmission electron microscope operating at $200 \mathrm{kV}$ and resolution $0.23 \mathrm{~nm}$. ESR spectra of all the samples were recorded from $150 \mathrm{~K}$ to $300 \mathrm{~K}$ on Carl JES X3 series ESR spectrometer operating at $\mathrm{X}$ band frequency $(v=9.198 \mathrm{GHz}) .{ }^{57} \mathrm{Fe}$ and ${ }^{55} \mathrm{Fe}$ Mossbauer absorption spectra were recorded in transmission geometry at room temperature using a multichannel analyzer with a drive in constant acceleration mode; ${ }^{57} \mathrm{Co}(\mathrm{Rh})$ source with initial activity of $20 \mathrm{mCi}$ was used. Magnetic properties of the compounds were measured using vibration sample magnetometer (VSM). The magnetization loops ( $\mathrm{M}$ versus H) of all samples were carried out at 5, 150, 200, 255 and $300 \mathrm{~K}$ using VSM in a fields up to $80 \mathrm{kOe}$.

\section{RESULT AND DISCUSSION}

\section{Micro and crystal structure}

Figure 1 presents the X-ray diffraction patterns of all barium ferrite samples of $\mathrm{Ba}_{1-\mathrm{x}}\left(\mathrm{Cu}_{\mathrm{x}} \mathrm{Al}_{\mathrm{x}} \mathrm{Fe}_{12-\mathrm{x}}\right) \mathrm{O}_{19}$. The $\mathrm{X}$-ray diffraction patterns of all the species are similar with very sharp peaks which indicate that all have hexagonal crystal structures. No additional phases and impurities are found.

Using X-ray data, lattice constants are calculated and are in the range of $5.8827 \AA$ to $5.777 \AA$ and $23.195 \AA$ to $23.00 \AA$ for $a$ and $c$ respectively. The lattice constant $a$ is found to decrease with increase of $\mathrm{Cu} / \mathrm{Al}$ concentration (x), the lattice constant $c$ decreases when $\mathrm{x}$ is increased up to 0.25 and then remains constant at concentration $\mathrm{x}=0.50,0.75$ and

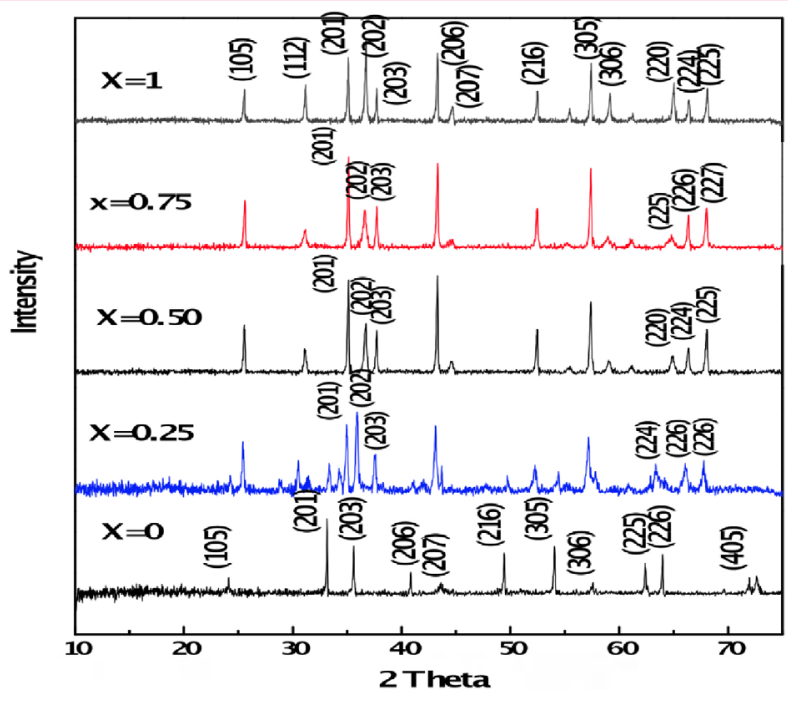

Figure 1. XRD pattern of $\mathrm{Ba}_{1-\mathrm{x}}\left(\mathrm{Cu}_{\mathrm{x}} \mathrm{Al}_{\mathrm{x}} \mathrm{Fe}_{12-\mathrm{x}}\right) \mathrm{O}_{19}$ compound.

1.00. This indicates that the change of the minor axis (a-axis) is larger than that of major ' $c$ ' axis for the substitution of $\mathrm{Cu}^{2+} / \mathrm{Al}^{3+}$ ions. This behavior is attributed to the substitution of $\mathrm{Fe}^{3+}$ ions which are of larger ionic radii $(0.064 \mathrm{~nm})$ compared with $\mathrm{Al}^{3+}$ ions $(0.054 \mathrm{~nm})$, and the substitution of $\mathrm{Ba}^{2+}$ ions which are of larger ionic radius $(0.134 \mathrm{~nm}) \mathrm{com}-$ pared with $\mathrm{Al}^{3+}$ ions $(0.054 \mathrm{~nm})$ and $\mathrm{Cu}^{2+}$ ions $(0.078 \mathrm{~nm})$. The ionic radii sum of $\mathrm{Al}^{3+}$ ions and $\mathrm{Cu}^{2+}$ ions are 0.132 $\mathrm{nm}$ and is almost the same as $\mathrm{Ba}^{2+}$ ionic radius. Thus in addition to normal doping of $\mathrm{Al}^{3+}$ in $\mathrm{Fe}^{3+}$, double doping of $\mathrm{Al}$ and $\mathrm{Cu}$ into $\mathrm{Ba}$ site takes place. Hence the noticeable value of cell size decreases and resulting low cell constant. Using Debye-Scherrer equation, the particle size is evaluated from the line broadening of the peak (203) which changes from 125 to $100 \mathrm{~nm}$.

Figure 2(a-c) shows TEM images of the un-doped $(\mathrm{x}=$ $0.00)$, doped $(0.50)$ and maximum doped $(\mathrm{x}=1.0)$ samples respectively. It is noticed that the hexaferrite particles are well defined with polygonal octahedral, tetrahedral and bipyramidal shapes (shown in Figure 2(a) at $\mathrm{x}=0.0$ ) and are well joined. From nano-chemistry point of view, the adjacent particles which have common crystallographic orientation collide each other leading to coalescence. Adjacent primary particles attach to each other and form aggregates.

It is evident from Figure 2(b) $(x=0.50)$ that the particle size decreases with doping when compared to undoped ferrite. When doping is maximum, $\mathrm{x}=1.0$, as shown in Figure 2(c), the particle size is further reduced. The particles prepared from higher $\mathrm{Cu} / \mathrm{Al}$ concentration are discrete. The decrease in agglomeration is due to the
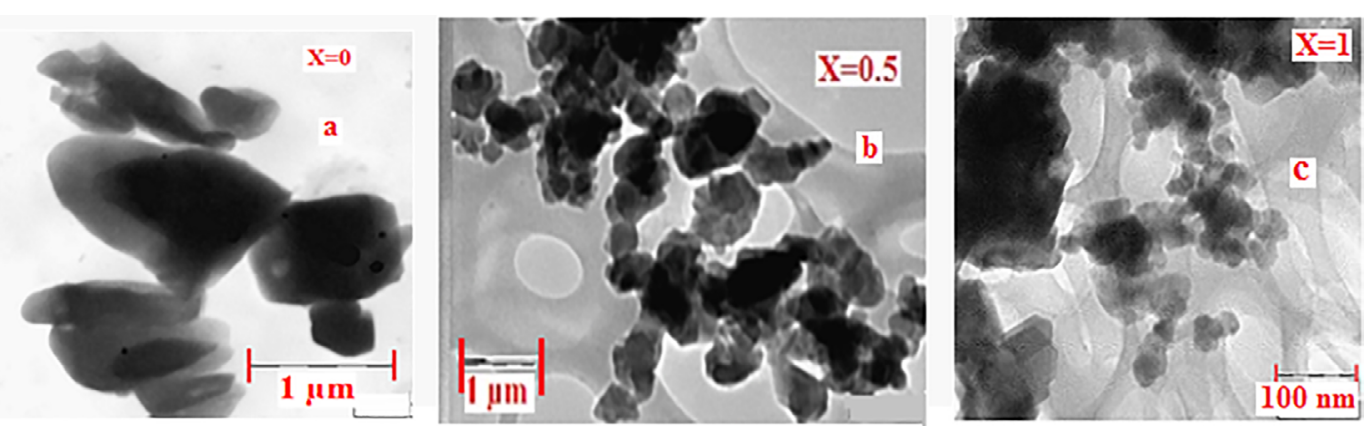

Figure 2. TEM images synthesized $\mathrm{Ba}_{1-\mathrm{x}}\left(\mathrm{Cu}_{\mathrm{x}} \mathrm{Al}_{\mathrm{x}} \mathrm{Fe}_{1-\mathrm{x}}\right) \mathrm{O}_{19}$. 
replacement of $\mathrm{Fe}^{3+}$ ions by $\mathrm{Al}^{3+}$ ions. Further replacement of $\mathrm{Ba}^{2+}$ ion by both $\mathrm{Cu}^{2+}$ and $\mathrm{Al}^{3+}$ ions leads to decrease in radii of cations. This results in the decrease of grain size. Hence the lattice constant decreases. This suggests that adjacent particles which do not have common crystallographic orientation do not collide with each other and thus they are appearing as separate particles. Also it is seen that the particle size decreases with increase of $\mathrm{Cu}$ / $\mathrm{Al}$ concentration. From Figure 2, it is observed that the particle size is drastically affected with increase of $\mathrm{Cu}$ / $\mathrm{Al}$ composition. The particle size distribution is broader and indicates the polycrystalline nature. The particles size varies from $98 \mathrm{~nm}, 95 \mathrm{~nm}, 69 \mathrm{~nm}, 78 \mathrm{~nm}$ and $61 \mathrm{~nm}$ when $\mathrm{x}$ is increased from $\mathrm{x}=0.00$ to 1.00 in steps of 0.25 . The particle size is large at $\mathrm{x}=0.0$ and small at $\mathrm{x}=1.0$. The ratio of particle size is about 10:6 (without doping vs maximum doping).

\section{Magnetic properties}

Bulk hexaferrite $\mathrm{BaFe}_{12} \mathrm{O}_{19}$ is a classic magnetic material with $\mathrm{Tc}=725 \mathrm{~K}$ and exhibits very high uniaxial anisotropy. When the same compound is in nanoscale form, its magnetic state changes drastically ${ }^{1,20}$.

Figure 3 shows magnetization $(\mathrm{M} \mathrm{emu} / \mathrm{g})$ versus temperature $(\mathrm{T} / \mathrm{K})$ behavior of $\mathrm{Ba}_{1-\mathrm{x}}\left(\mathrm{Cu}_{\mathrm{x}} \mathrm{Al}_{\mathrm{x}} \mathrm{Fe}_{12-\mathrm{x}}\right) \mathrm{O}_{19}(\mathrm{x}=0.0$ to 1.0) samples under both Zero-Field-Cooled (ZFC) and Field-Cooled (FC) conditions in an applied magnetic field of 80,000 Oe. ZFC curves were obtained by cooling the sample from $300 \mathrm{~K}$ to $5 \mathrm{~K}$ without applying an external magnetic field. In the case of FC temperature of the sample after reaching $5 \mathrm{~K}$, an 80,000 Oe magnetic field was applied and the magnetization was recorded as the temperature was increased. From these curves blocking temperature is known. This is the temperature at which branching of ZFC and $\mathrm{FC}$ curves merge together or where a maximum in magnetization in the ZFC data is seen.

In the present study nearly temperature independent magnetization behavior have been seen between $300 \mathrm{~K}$ to $150 \mathrm{~K}$ except for $\mathrm{x}=0.50$. For this compound raise in the magnetization below $250 \mathrm{~K}$ was observed and attributed to paramagnetic phase. Below $T_{B}$ magnetic susceptibility decreases with decrease of temperature. This behavior is characteristic of super paramagnetism present in the compound.

As can be seen from Figure 3, the un-doped sample $(x=0.0)$ shows a high magnetization when compared to the

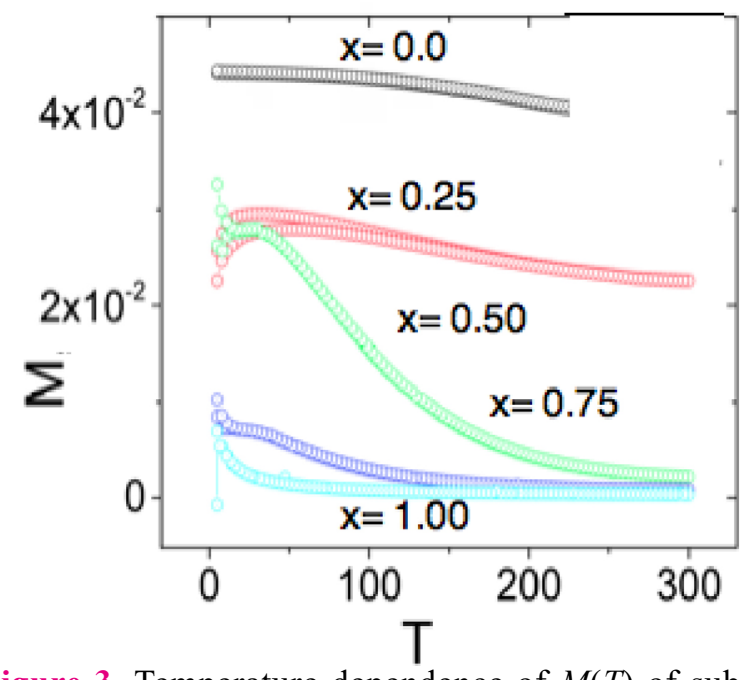

Figure 3. Temperature dependence of $M(T)$ of substituted Ba-ferrite.

doped samples; it changes slightly with increase of temperature. A similar trend is observed in doped sample when $\mathrm{x}=0.25$. In this compound the magnetization decreases by about $40 \%$ relative to the pure ferrite. In this compound $\mathrm{T}_{B}$ is noticed as $150 \mathrm{~K}$. The magnetization is zero beyond $\mathrm{T} \geq$ $150 \mathrm{~K}$. When $\mathrm{x} \geq 0.5$, a qualitatively different dependence inherent to super-paramagnetic state is observed. In these compounds $\mathrm{T}_{\mathrm{B}}$ is found to be approximately $25 \mathrm{~K}, 20 \mathrm{~K}$ and $10 \mathrm{~K}$ for $\mathrm{x}=0.50,0.75$ and 1.00 respectively. These results suggest that $\mathrm{T}_{B}$ decreases with the increase of $\mathrm{Cu} / \mathrm{Al}$ content. At room temperature, no magnetic property is noticed with $\mathrm{x}=0.75$ and 1.0 .

In the present case, when $x=0.75$, the magnetization is almost zero at $\mathrm{T} \geq 200 \mathrm{~K}$. Previous reports ${ }^{12}$ indicate that substitution of $\mathrm{Al}$ even up to $\mathrm{x}=4.0$ in the compound results in weak magnetization. Using Mossbauer spectroscopy, they explained that $\mathrm{Al}$ ions preferentially occupy the octahedral site $4 \mathrm{f}_{2}, 2 \mathrm{a}, 12 \mathrm{k}$ and $4 \mathrm{f}_{1}$ at $\mathrm{x} \leq 2.0$.

The magnetization measurements $(\mathrm{M}$ verses $\mathrm{H})$ of all $\mathrm{Ba}_{1-\mathrm{x}}\left(\mathrm{Cu}_{\mathrm{x}} \mathrm{Al}_{\mathrm{x}} \mathrm{Fe}_{12-\mathrm{x}}\right) \mathrm{O}_{19}(\mathrm{x}=0$ to 1.0$)$ nano samples are carried out at $5,100,200,255$ and $300 \mathrm{~K}$ using vibrating sample magnetometer (VSM) in a field of 80000 Oersted. The measured hysteresis loops for $\mathrm{Ba}_{1-x}\left(\mathrm{Cu}_{\mathrm{x}} \mathrm{Al}_{\mathrm{x}} \mathrm{Fe}_{12-\mathrm{x}}\right) \mathrm{O}_{19}$ samples as a function of the applied magnetic field are shown in Figure 4(a-b). Magnetization is normalized to the maximum value for each curve at $30 \mathrm{kOe}$ for better data comparison. From Figure 4(a), we notice that there are three different cases: For undoped
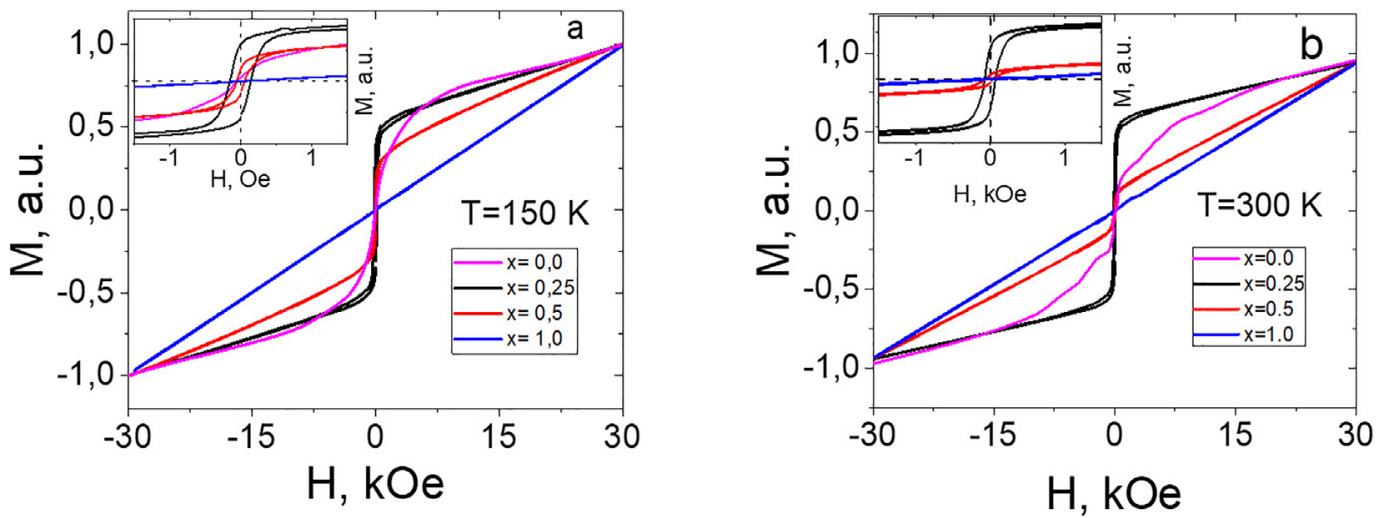

Figure 4. $\mathrm{Ba}_{1-\mathrm{x}}\left(\mathrm{Cu}_{\mathrm{x}} \mathrm{Al}_{\mathrm{X}} \mathrm{Fe}_{12-\mathrm{x}}\right) \mathrm{O}_{19}$ hysteresis loops for different temperatures. 
$\mathrm{BaFe}_{12} \mathrm{O}_{19}$ sample $(\mathrm{x}=0.0), M(H)$ curve shows no hysteresis and its residual magnetization is an indication of superparamagnetic state $^{21}$. Completely doped sample $(\mathrm{x}=1.0) M(H)$ show typical behavior of paramagnetic nature and its magnetization linearly increases with increase of magnetic field. In all other cases, the compound shows combined behavior. Thus, on one hand, the symmetric loop of hysteresis is clearly visible and on the other hand, the magnetization does not reach to saturation even at high field. When temperature increases to 300 $\mathrm{K}$, there are no qualitative changes in $M-H$ curves. When $\mathrm{x}$ $=0.50$, there is a decrease in residual magnetization. Further when $\mathrm{x}=0.25$, the residual magnetism $\mathrm{H}_{\mathrm{c}}$ is $0.3 \mathrm{kOe}$ at $100 \mathrm{~K}$ and it decreases to $0.15 \mathrm{kOe}$ at $300 \mathrm{~K}$.

In $\mathrm{BaFe}_{12} \mathrm{O}_{19}$ nano ferrite system, there are five non-equivalent sub-lattices, of which three are octahedral $(2 \mathrm{a}, 12 \mathrm{k}$, and $4 \mathrm{f}_{2}$ ), one tetrahedral $\left(4 \mathrm{f}_{1}\right)$ and one trigonal bipyramidal $(2 \mathrm{~b})^{22}$. In the $\mathrm{Ba}_{1-\mathrm{x}}\left(\mathrm{Cu}_{\mathrm{x}} \mathrm{Al}_{\mathrm{x}} \mathrm{Fe}_{12-\mathrm{x}}\right) \mathrm{O}_{19}$ nano compounds, $\mathrm{Fe}^{3+}$ ions are partially replaced by an equal amounts of $\mathrm{Cu}^{2+}$ and $\mathrm{Al}^{3+}$ ions, similarly $\mathrm{Ba}^{2+}$ ions are replaced by both $\mathrm{Al}^{3+}$ and $\mathrm{Cu}^{2+}$ ions. Now when the diamagnetic $\mathrm{Al}^{3+}$ ions are substituted by $\mathrm{Fe}^{3+}$ ions, it results in decrease of the magnetic saturation $\left(\mathrm{M}_{\mathrm{s}}\right)$ value because of the super exchange interaction $\left(\mathrm{Fe}^{3+}-\mathrm{O}-\mathrm{Fe}^{3+}\right)$ since the $\mathrm{Al}^{3+}$ ions preferentially occupy the octahedral 2a site followed by $12 \mathrm{k}$ and $4 \mathrm{f}_{2} \operatorname{sites}^{23}$. Introduction of $\mathrm{Cu}^{2+}$ and $\mathrm{Al}^{3+}$ into the tetrahedral site does not change the net magnetization of the ferrite compound but replacement of $\mathrm{Cu}^{2+}$ ions in octahedral sites resulted in the variation of the net magnetization of the materials ${ }^{24}$. Thus all the magnetic properties are found to decrease with the increase of $\mathrm{Cu} / \mathrm{Al}$ contents, which is due to the occupation of the doped cations at the octahedral sites $(12 \mathrm{k}$ and 2a) having a spin of electrons in an upward direction.

Previous reports ${ }^{25}$ indicate that substitution of $\mathrm{Cu} / \mathrm{Al}$ in tetrahedral and octahedral sites in cobalt ferrite lowers the magnetization values. In our compounds, similar trend is noticed suggesting that $\mathrm{Cu} / \mathrm{Al}$ doping enters both tetrahedral and octahedral sites which results in decreasing of the magnetic properties.

It is well known that the size of nanoparticles has a strong influence on the magnetic properties ${ }^{26}$. In the case of our samples, it has been found that substitution affects the size of nanoparticles. This gives the possibility of partially eliminating the size effect in magnetic properties. For further investigation of the magnetic state, the method of electron spin resonance is used. This powerful method, in some cases, allows us to separate the magnetic phases of magnetic materials including complex oxides ${ }^{27-29}$.

\section{Resonance study}

The results of VSM measurement are confirmed by Electron Spin Resonance spectroscopy. ESR spectra recorded for barium ferrite powder $\mathrm{Ba}_{1-\mathrm{x}}\left(\mathrm{Cu}_{\mathrm{x}} \mathrm{Al}_{\mathrm{x}} \mathrm{Fe}_{12-\mathrm{x}} \mathrm{O}_{19}\right)$ in the range $150 \mathrm{~K}$ to $300 \mathrm{~K}$ are shown in Figure 5. $\mathrm{Fe}^{3+}$, a d $\mathrm{d}^{5}$ ion with ${ }^{6} \mathrm{~S}_{5 / 2}$ spin state splits into three Kramer's doublets, separated by nearly $1.0 \mathrm{~cm}^{-1}$. In this case, only the lowest doublet is populated and one can observe resonances at $g=9.0^{14,15,30,31}$. On the other hand, if the middle Kramer's doublet is also populated, a $\mathrm{g}$ value of 4.29 is expected. If third doublet is also populated, $g$ values ranging from 0.3 to 4.29 can be seen.

ESR spectra recorded for nano powder $\left(\mathrm{BaFe}_{12} \mathrm{O}_{19}\right)$ in the range $150 \mathrm{~K}$ to $300 \mathrm{~K}$ is shown in Figure 5(a). It is seen that only a resonant signal with strongly symmetric resonance at all temperatures with same $g$ value of 2.12 , varying line intensity and width is noticed. It is attributed to the ions $\mathrm{Fe}$ (III) distributed in octahedral coordinate sites. It is ascribed to the ferrimagnetic resonance exhibited by $\mathrm{Fe}(\mathrm{III})$ cations in the ferrite at different interstitial sites that couple anti-ferromagnetically due to a super exchange interac$\operatorname{tion}^{17,29,32}$. The line-width of EPR signal may be due to magnetic dipole interactions among the particles or super exchange interactions between the magnetic ions through the oxygen ions. If dominant dipole interactions are present in the compound large line-width and g-factor occurs, whereas super exchange interactions are dominant small-linewidth and lower g-values are observed ${ }^{19,33}$. Occurrence of narrow peak-to-peak line-width at room temperature in the sample may be due to dominant super exchange interaction. As $\mathrm{Cu} / \mathrm{Al}$ doping progresses, line splitting is observed. The similar results were observed by the authors ${ }^{27}$.

EPR spectra of nano $\left(\mathrm{Cu}_{0.50} \mathrm{Ba}_{0.50}\right)\left(\mathrm{Al}_{0.50} \mathrm{Fe}_{11.50}\right) \mathrm{O}_{19}$ recorded in the range 150 to $300 \mathrm{~K}$ is shown in Figure 5(b). The spectrum is characteristic of $\mathrm{Fe}(\mathrm{III})$ and $\mathrm{Cu}(\mathrm{II})$. The calculated $\mathrm{g}$ values are 4.0, 2.25 are ascribed to $\mathrm{Fe}(\mathrm{III})$ and $\mathrm{Cu}(\mathrm{II})$ respectively. In particular at $250 \mathrm{~K}$ the observed $\mathrm{g}$ values are 2.74 and 2.18 which may be due to the superimposition of $\mathrm{Fe}$ (III) resonant signal with $\mathrm{g} \cong 2.18$.

EPR spectra of nano $\left(\mathrm{Cu}_{0.75} \mathrm{Ba}_{0.25}\right)\left(\mathrm{Al}_{0.75} \mathrm{Fe}_{11.25}\right) \mathrm{O}_{19}$ recorded in the range of $150 \mathrm{~K}-300 \mathrm{~K}$ is shown in Figure 5(c). The spectrum is resolved with characteristic of $\mathrm{Fe}(\mathrm{III})$ and $\mathrm{Cu}$ (II) signals. At $250 \mathrm{~K}$, the observed resonant signals give $\mathrm{g}$ values $5.67,3.65$ and 2.25 which are ascribed to $\mathrm{Fe}(\mathrm{III})$ and $\mathrm{Cu}(\mathrm{II})$ respectively. This suggests that as $\mathrm{Cu} / \mathrm{Al}$ concentration increases the nano compound reducing its ferromagnetic character and slowly converting into super paramagnetic nature. Further we notice that the $\mathrm{Cu}$ is entering into tetragonal distortion ${ }^{34}$.

EPR spectrum of completely doped $\mathrm{Cu}\left(\mathrm{AlFe}_{11}\right) \mathrm{O}_{19}$ nano compound recorded in the temperature range of $150 \mathrm{~K}$ to 300 $\mathrm{K}$ is shown in Figure 5(d). The spectrum is well resolved with five resonant signals ranging from low to high field. These five resonant signals indicate that the compound may have five $\mathrm{Fe}(\mathrm{III})$ sites. These signals are due to $\mathrm{Fe}^{3+}$ and $\mathrm{Cu}^{2+}$. Thus the compound is super-paramagnetic in nature. This is explained as follows: It is assumed that $\mathrm{Ba}^{2+}$ is totally replaced by $\mathrm{Cu}^{2+}$ and only one $\mathrm{Fe}^{3+}$ is replaced by diamagnetic $\mathrm{Al}^{3+}$ ions in the unit cell. Thus paramagnetic behavior of $\mathrm{Cu}^{2+}$ is dominated. From the spectrum, the $\mathrm{g}$ values obtained for $\mathrm{Cu}^{2+}$ are $\mathrm{g}_{11}=$ 2.70 and $\mathrm{g}_{\perp}=2.27$ which indicate that $\mathrm{Cu}^{2+}$ is in tetragonal distortion. Tetragonal cupric complexes with $\mathrm{D}_{4 \mathrm{~h}}$ generally have $\mathrm{g}_{11}$ (corresponding to the magnetic field along the $\mathrm{Z}$ axis of the complexes) $>g_{\perp}>2.04$ have the ground state $d_{x^{2}-y^{2}}{ }^{35-37}$. In the present case $g_{11}>g_{\perp}>2.00(2.70>2.27>2.0036)$ and

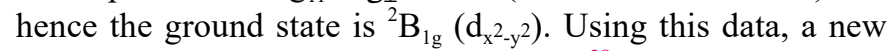
parameter $\mathrm{G}=\left(\mathrm{g}_{11}-\mathrm{g}_{\mathrm{e}}\right) /\left(\mathrm{g}_{\perp}-\mathrm{g}_{\mathrm{e}}\right)$ is defined ${ }^{38}$ and calculated as $\cong$ 2.61. If $G$ value falls in between 3 and 5 , the unit cell contains magnetically non-equivalent ions. If $G$ value is less than 3 , the exchange coupling among the magnetically non equivalent $\mathrm{Cu}(\mathrm{II})$ ions in the unit cell is not very strong. If $\mathrm{G}$ is greater than 5, a strong exchange coupling takes place among the magnetically non equivalent $\mathrm{Cu}$ (II) ions in the unit cell ${ }^{39-42}$. In the present case $G$ is less than 3.0 (observed values is 2.61), which indicates that the unit cell contains magnetically nonequivalent ions and the coupling is not very strong. As the 
(a)

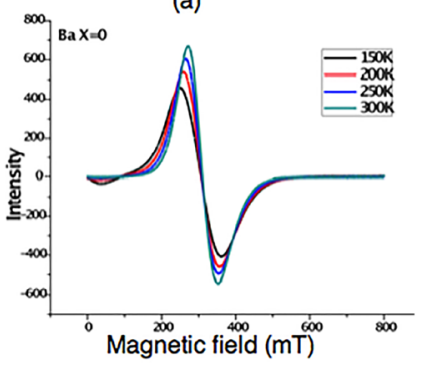

(c)

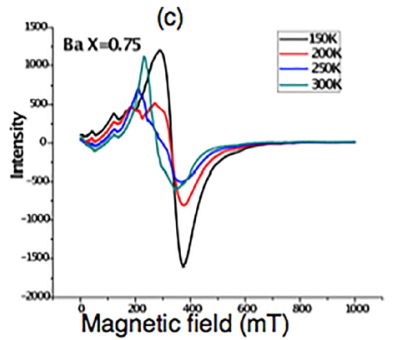

(b)
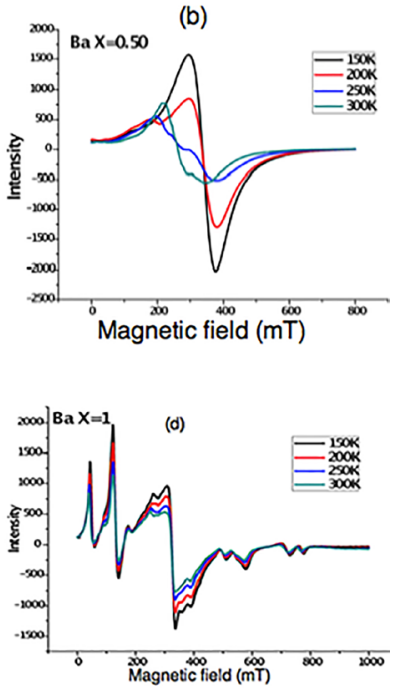

Figure 5. EPR spectrum of nano $\mathrm{Ba}_{1-\mathrm{x}}\left(\mathrm{Cu}_{\mathrm{x}} \mathrm{Al}_{\mathrm{x}} \mathrm{Fe}_{12-2 \mathrm{x}}\right) \mathrm{O}_{19}$ powder.

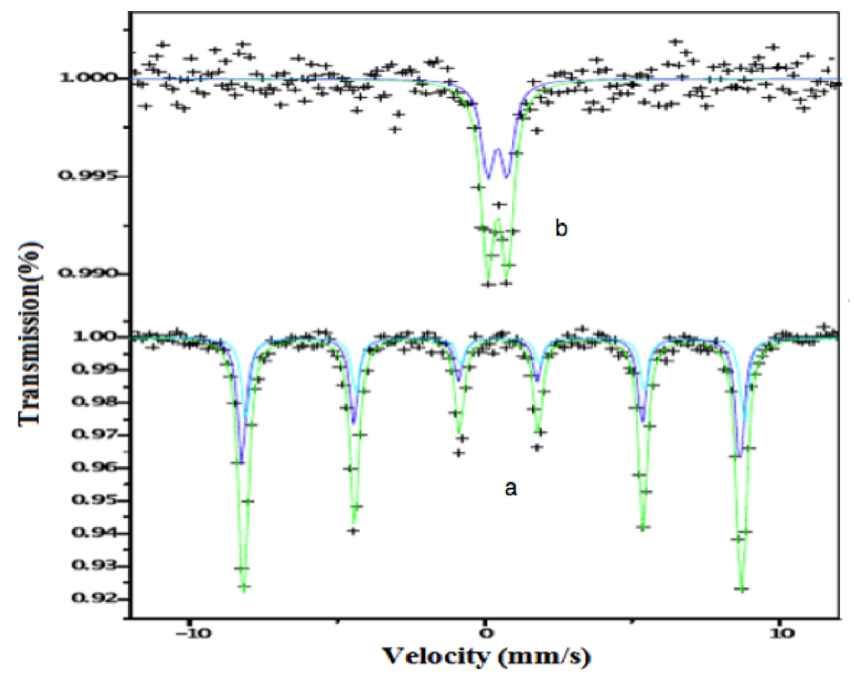

Figure 6. Mossbauer absorption spectra of system

(a) $\mathrm{BaFe}_{12} \mathrm{O}_{19}$ and (b) $\mathrm{CuAlFe}_{11} \mathrm{O}_{19}$.

ferrite contains a very high percentage of iron, the resonant signals due to $\mathrm{Fe}^{3+}$ are also noticed with $\mathrm{g}$ values at 9.0, 4.96, 2.04. Thus the EPR results indicate that the $\mathrm{CuAlFe}{ }_{11} \mathrm{O}_{19}$ ferrite nano-crystal is in distorted octahedron structure. The resonant signals observed at higher magnetic field shown in Figure 5(d) have $g$ values of 1.20 and 0.90. Such a low $g$ values may not be due to $\mathrm{Cu}(\mathrm{II})$. Since the compound contains $\mathrm{Cu}, \mathrm{Al}, \mathrm{Fe}$ and $O^{2-}$. Generally a free radical $O^{2-}$ gives a resonant signal around DPPH. Also Al is diamagnetic. Hence the resonant values are not due to $\mathrm{Al}, \mathrm{O}^{2-}$ and $\mathrm{Cu}(\mathrm{II})$. Thus these are assigned to Fe(III) which is occupied by third Kramer's doublet given in the theory earlier. Thus the compound with $\mathrm{x}=1.0$ is completely paramagnetic. This result confirmed the magnetic measurements shown in Figure 4. The sample with complete substitution has zero magnetization at $200 \mathrm{~K}$ and as the concentration of $\mathrm{Cu} / \mathrm{Al}$ increases, saturation magnetization $\left(M_{\mathrm{s}}\right)$ also increases.

From Figure 4(b) $(\mathrm{x}=0.5)$, the temperature evolution of the magnetic state is observed. At a low temperature, the almost symmetric resonance line is observed. However, as temperature progresses the appearance of an additional signal is observed. At $300 \mathrm{~K}$, two clear lines are observed. This suggests that the samples exhibit a weak ferromagnet-

ic nature and significant paramagnetic nature (remanence is equal to $7 \%$ of normalized M). But from Figure 4(a), it is observed that the ferromagnetic behavior is large (30\%) at low temperature. Thus these results suggest that coexistence of two magnetic phases in the compound.

${ }^{55} \mathrm{Fe}$ Mossbauer absorption spectra of hexagonal ferrite system $\mathrm{Ba}_{1-\mathrm{x}}\left(\mathrm{Cu}_{\mathrm{x}} \mathrm{Al}_{\mathrm{x}} \mathrm{Fe}_{12-\mathrm{x}}\right) \mathrm{O}_{19}$ for $\mathrm{x}=0.0$ and 1.0 were recorded at room temperature. The result is shown in Figure 6. It can be seen from Figure 6(b) that the spectrum of $\mathrm{BaFe}_{12} \mathrm{O}_{19}$ exhibits a superimposition of two Zeeman sextets, which indicates the ferrimagnetic behavior of the sample. The sample is polycrystalline in nature and the presence of any texture is unlikely; the widths and heights of the six lines of each sextet are constrained during fitting so that the area ratio of the lines $(1,6)$ : $(2,5):(3,4)$ becomes $3: 2: 1$. One sextet (outer) corresponding to a higher magnetic field is attributed to $\mathrm{Fe}^{3+}$ ions in the octahedral (B)-site and the other sextet (inner) corresponding to the lower magnetic field is attributed to $\mathrm{Fe}^{3+}$ ions in the tetrahedral (A)- site. For the sample, $\mathrm{BaFe}_{12} \mathrm{O}_{19}$, the sextet with lowest isomer shift (IS) $(0.34 \mathrm{~mm} / \mathrm{s})$ is attributed to $\mathrm{Fe}^{3+}$ ions in tetrahedral sites. The other sextet with higher IS $(0.45 \mathrm{~mm} / \mathrm{s})$ is attributed to $\mathrm{Fe}^{3+}$ ion in the octahedral site (B). The isomer shift of octahedral sites is greater than that in the tetrahedral site and is in agreement with the reported data ${ }^{43}$. Further, the quadrupole splitting (QS) observed for the tetrahedral site is greater than that of the octahedral site, which indicates that the tetrahedral site is higher asymmetric for $\mathrm{Fe}^{3+}$. Also the observed values $(0.45$ and $0.34 \mathrm{~mm} / \mathrm{s})$ of isomer shift $(\delta)$ are significantly less than the expected value, $0.5 \mathrm{~mm} / \mathrm{s}$ for the $\mathrm{Fe}^{2+}$ ions ${ }^{44}$. Hence, the Mossbauer spectrum of pure Ba ferrite is not affected by the relaxation process. Thus the presence of $\mathrm{Fe}^{2+}$ ions in the present ferrite system is ruled out. Therefore the electron exchange interaction $\left(\mathrm{Fe}^{2+} \leftrightarrow \mathrm{Fe}^{3+}+\mathrm{e}^{-}\right)$does not occur and hence the oxidation state of $\mathrm{Fe}^{3+}$ remains unchanged during the synthetic process. Decrease in isomer shift may indicate lowering of coordination number of $\mathrm{Fe}^{3+}$ ions which is usually small ${ }^{45}$. But the increase $(0.17,0.24 \mathrm{~mm} / \mathrm{s})$ in the quadrupole splitting indicates a loss of symmetry of $\mathrm{Fe}^{3+}$ ions to the highly distorted octahedral environment. Quadrupole splitting increases with increase of $\mathrm{Cu} / \mathrm{Al}$. These results indicate that $\mathrm{Ba}$ ferrite lattice shows a distortion. The area ratio of $\mathrm{Fe}^{3+}$ octahedral to the tetrahedral site is obtained from the Mossbauer spectra $\mathrm{BaFe}_{12} \mathrm{O}_{19}$ is $39.7 / 60.9=0.6519$ which is in good agreement with that calculated from X-ray intensities (not discussed in the XRD analysis). It is observed that this ratio decreases with increasing $\mathrm{Cu} / \mathrm{Al}$ concentration suggesting a decrease in ferrimagnetic behavior and converting the same into paramagnetic ${ }^{12}$.

Figure 6(a) shows the Mossbauer spectrum (MS) of maximum substituted $\mathrm{Cu} / \mathrm{Al}$ concentration in the ferrite. The presence of doublet indicates the characteristic features of paramagnetic behavior. The relaxation of paramagnetic nanoparticles at a faster rate than that of MS measurement time $\left(10^{-9} \mathrm{~s}\right)$ causes in double. A significant change in the isomer shift $(0.24 \mathrm{~mm} / \mathrm{s})$ of ferrite is observed with progressive doping of $\mathrm{Cu}^{2+} / \mathrm{Al}^{3+}$ ions. This indicates that the s-electron charge distribution of $\mathrm{Fe}^{3+}$ ion is influenced by $\mathrm{Al}$ substitution. The sample with $\mathrm{x}=1.0$ is paramagnetically relaxed, and the relaxation in these sample decreases while intensity of the paramagnetic doublet increases. This may be due to the interaction of the electric field gradient (EFG) with 
the quadrupole moment of ${ }^{57} \mathrm{Fe}$ nucleus and the reduction of interaction between $\mathrm{Fe}$ ions and octahedral $\mathrm{Al}^{3+}$ ions. The analysis of the data shows that quadrupole splitting $(0.66$ $\mathrm{mm} / \mathrm{s}$ ) increases with the increase of doping. The quadrupole doublet pattern clearly shows that the sample exhibits paramagnetism. The results obtained are in consistent with the results of the vibrational sample magnetometer and electron paramagnetic resonance spectroscopy.

\section{CONCLUSIONS}

Nano-size particles of $\mathrm{Cu} / \mathrm{Al}$ substituted barium hexaferrite $\mathrm{Ba}_{1-\mathrm{x}}\left(\mathrm{Cu}_{\mathrm{x}} \mathrm{Al}_{\mathrm{x}} \mathrm{Fe}_{12-\mathrm{x}}\right) \mathrm{O}_{19}, \mathrm{x}=(0.0-1.0)$ have been synthesized by solid-state route method. X-ray diffractometry and TEM showed that the size of synthesized nanoparticles is about 100 $\mathrm{nm}$ and the doping by $\mathrm{Cu} / \mathrm{Al}$ leads to a large decrease in their sizes. Magnetic properties are found to decrease with the increase of $\mathrm{Cu} / \mathrm{Al}$ content which is due to the occupation of the doped cations at the octahedral and tetrahedral sites. The magnetization of the un-doped sample is high and is very slightly dependent on temperature. At the same time, magnetization of maximum-doped $(\mathrm{x}=1.0)$ sample is weak. The study of $M(H)$ dependence of $\mathrm{BaFe}_{12} \mathrm{O}_{19}$ showed that there is no residual magnetization in the sample and shows almost no hysteresis. When $\mathrm{x}=1.0$ the sample is completely paramagnetic. This is confirmed by the linear dependence of magnetization and EPR studies which has a low value. At intermediate concentrations $(0<\mathrm{x}<1)$, they show a small loop of hysteresis where coercivity $\left(H_{\mathrm{C}}\right)$ was up to $300 \mathrm{Oe}$, but they do not reach saturation in large fields. This suggests the coexistence of strongly (ferrimagnetic) and weakly (paramagnetic) behavior which is confirmed by ESR. Mossbauer spectroscopy further confirmed that nanoparticles of un-doped samples have strong-magnetic properties (ferrimagnetic) and completely doped ( $\mathrm{x}=$ 1.0) samples have weak magnetic properties (paramagnetic). Considering the results and literature data, we assume that the double substitution greatly changes the magnetic properties of individual nanoparticles. This leads to the fact that the ensembles of these particles change their behavior (Super PM - PM/ $\mathrm{FM}-\mathrm{PM}$.

\section{Notes}

The authors declare no competing financial interest.

\section{References}

[1] Pullar RC. Hexagonal ferrites: A review of the synthesis, properties and applications of hexaferrite ceramics. Progress in Materials Science. 2012;57(7):1191-334. doi:10.1016/j.pmatsci.2012.04.001

[2] Kostishyn VG, Panina LV, Timofeev AV, Kozhitov LV, Kovalev AN, Zyuzin AK. Dual ferroic properties of hexagonal ferrite ceramics $\mathrm{BaFe}_{12} \mathrm{O}_{19}$ and $\mathrm{SrFe}_{12} \mathrm{O}_{19}$. Journal of Magnetism and Magnetic Materials. 2016;400:327-32. doi:10.1016/j.jmmm.2015.09.011 [3] Dagotto E, Hotta T, Moreo A. Colossal magnetoresistant materials: the key role of phasearation. Physics Reports. 2001;344(13):1-153. doi:10.1016/s0370-1573(00)00121-6

[4] Turchenko V, Trukhanov A, Trukhanov S, Bobrikov I, Balagurov AM. Features of crystal and magnetic structures of solid solutions $\mathrm{BaFe}_{12-\mathrm{x}} \mathrm{D}_{\mathrm{x}} \mathrm{O}_{19}\left(\mathrm{D}=\mathrm{Al}^{3+}, \mathrm{In}^{3+} ; \mathrm{x}=0.1\right)$ in a wide temperature range. The European Physical Journal Plus. 2016;131(4). doi:10.1140/epjp/i2016-16082-x
[5] Nikmanesh H, Moradi M, Bordbar GH, Shams Alam R. Effect of multi dopant barium hexaferrite nanoparticles on the structural, magnetic, and $\mathrm{X}-\mathrm{Ku}$ bands microwave absorption properties. Journal of Alloys and Compounds. 2017;708:99-107. doi:10.1016/ j.jallcom.2017.02.308

[6] Wearing D, Horsfield AP, Xu W, Lee PD. Which wets $\mathrm{TiB}_{2}$ inoculant particles: $\mathrm{Al}$ or $\mathrm{Al}_{3} \mathrm{Ti}$. Journal of Alloys and Compounds. 2016;664:460-8. doi:10.1016/j.jallcom.2015.12.203

[7] Mosleh Z, Kameli P, Poorbaferani A, Ranjbar M, Salamati H. Structural, magnetic and microwave absorption properties of Cedoped barium hexaferrite. Journal of Magnetism and Magnetic Materials. 2016;397:101-7. doi:10.1016/j.jmmm.2015.08.078

[8] Awawdeh M, Bsoul I, Mahmood SH. Magnetic properties and Mössbauer spectroscopy on $\mathrm{Ga}, \mathrm{Al}$, and $\mathrm{Cr}$ substituted hexaferrites. Journal of Alloys and Compounds. 2014;585:465-73. doi:10.1016/j.jallcom.2013.09.174

[9] Tyrman M, Pasko A, De La Barrière O, Mazaleyrat F. Structural and magnetic properties of an anisotropic M-type LaCo-substituted strontium hexaferrite. Razek A, editor. The European Physical Journal Applied Physics. 2015;72(2):20601. doi:10.1051/ epjap/2015150099

[10] Trukhanov SV, Trukhanov AV, Kostishyn VG, Panina LV, Trukhanov AV, Turchenko VA, et al. Effect of gallium doping on electromagnetic properties of barium hexaferrite. Journal of Physics and Chemistry of Solids. 2017;111:142-52. doi:10.1016/ j.jpcs.2017.07.014

[11] Luo H, Rai BK, Mishra SR, Nguyen VV, Liu JP. Physical and magnetic properties of highly aluminum doped strontium ferrite nanoparticles prepared by auto-combustion route. Journal of Magnetism and Magnetic Materials. 2012;324(17):2602-8. doi:10.1016/j.jmmm.2012.02.106

[12] Dong Hyeok Choi, Sang Won Lee, Sung Yong An, SeungIel Park, In-Bo Shim, Chul Sung Kim. Mossbauer studies and magnetic properties of $\mathrm{BaFe}_{12-\mathrm{X}} \mathrm{Al}_{\mathrm{X}} \mathrm{O}_{19}$ grown by a wet chemical process. IEEE Transactions on Magnetics. 2003;39(5):2884-6. doi:10.1109/tmag.2003.815736

[13] Shayan A, Abdellahi M, Shahmohammadian F, Jabbarzare S, Khandan A, Ghayour H. Mechanochemically aided sintering process for the synthesis of barium ferrite: Effect of aluminum substitution on microstructure, magnetic properties and microwave absorption. Journal of Alloys and Compounds. 2017;708:538-46. doi:10.1016/j.jallcom.2017.02.305

[14] Vadivelan S, Victor Jaya N. Investigation of magnetic and structural properties of copper substituted barium ferrite powder particles via co-precipitation method. Results in Physics. 2016;6:843-50. doi:10.1016/j.rinp.2016.07.013

[15] Vinnik DA, Tarasova AY, Zherebtsov DA, Mashkovtseva LS, Gudkova SA, Nemrava S, et al. Cu-substituted barium hexaferrite crystal growth and characterization. Ceramics International. 2015;41(7):9172-6. doi:10.1016/j.ceramint.2015.03.051

[16] Ounnunkad S. Improving magnetic properties of barium hexaferrites by La or Pr substitution. Solid State Communications. 2006;138(9):472-5. doi:10.1016/j.ssc.2006.03.020

[17] Mosleh Z, Kameli P, Poorbaferani A, Ranjbar M, Salamati H. Structural, magnetic and microwave absorption properties of Cedoped barium hexaferrite. Journal of Magnetism and Magnetic Materials. 2016;397:101-7. doi:10.1016/j.jmmm.2015.08.078

[18] Ashiq MN, Javed Iqbal M, Hussain Gul I. Effect of Al-Cr doping on the structural, magnetic and dielectric properties of strontium hexaferrite nanomaterials. Journal of Magnetism and Magnetic Materials. 2011;323(3-4):259-63. doi:10.1016/j.jmmm.2010.08.054 
[19] Qi Y, Yang Y, Zhao X, Liu X, Wu P, Zhang F, et al. Controllable magnetic properties of cobalt ferrite particles derived from layered double hydroxide precursors. Particuology. 2010;8(3):207-11. doi:10.1016/j.partic.2010.03.008

[20] Trusov LA, Vasiliev AV, Lukatskaya MR, Zaytsev DD,sen M, Kazin PE. Stable colloidal solutions of strontium hexaferrite hard magnetic nanoparticles. Chem Commun. 2014 24;50(93):14581-4. doi:10.1039/c4cc03870c

[21] Kolhatkar A, Jamison A, Litvinov D, Willson R, Lee T. Tuning the Magnetic Properties of Nanoparticles. International Journal of Molecular Sciences. 2013 31;14(8):15977-6009. doi:10.3390/ ijms140815977

[22] Ngo AT, Bonville P, Pileni MP. Spin canting and size effects in nanoparticles of nonstoichiometric cobalt ferrite. Journal of Applied Physics. 2001 Mar 15;89(6):3370-6. doi:10.1063/1.1347001

[23] Goya GF, Rechenberg HR, Chen M, Yelon WB. Magnetic irreversibility in ultrafine $\mathrm{ZnFe}_{2} \mathrm{O}_{4}$ particles. Journal of Applied Physics. 2000;87(11):8005-7. doi:10.1063/1.373487

[24] Lechevallier L, Le Breton JM, Wang JF, Harris IR. Structural analysis of hydrothermally synthesized $\mathrm{Sr}_{1-\mathrm{x}} \mathrm{Sm}_{\mathrm{x}} \mathrm{Fe}_{12} \mathrm{O}_{19}$ hexagonal ferrites. Journal of Magnetism and Magnetic Materials. 2004;269(2):192-6. doi:10.1016/s0304-8853(03)00591-2

[25] DABAGH S, ATI AA, GHOSHAL SK, ZARE S, ROSNAN RM, JBARA AS, et al. $\mathrm{Cu}^{2+}$ and $\mathrm{Al}^{3+}$ co-substituted cobalt ferrite: structural analysis, morphology and magnetic properties. Bulletin of Materials Science. 2016 19;39(4):1029-37. doi:10.1007/s12034-0161233-8

[26] Kliava J, Berger R. Size and shape distribution of magnetic nanoparticles in disordered systems: computer simulations of superparamagnetic resonance spectra. Journal of Magnetism and Magnetic Materials. 1999;205(2-3):328-42. doi:10.1016/s03048853(99)00510-7

[27] Díaz-Pardo R, Bierlich S, Töpfer J, Monjaras RV. Electron spin resonance (ESR) of magnetic sublattices in Sc-substituted barium hexaferrite. AIP Advances. 2016;6(5):055202. doi:10.1063/1.4948796

[28] Yang J-T, Luo S-J, Xiong Y-C. Magnetic mechanism investigations on $\mathrm{K}$ and $\mathrm{Mn}$ co-doped diluted magnetic semiconductor $(\mathrm{Sr}, \mathrm{K})(\mathrm{Zn}, \mathrm{Mn})_{2} \mathrm{As}_{2}$. Journal of Magnetism and Magnetic Materials. 2016;407:334-40. doi:10.1016/j.jmmm.2016.02.012

[29] Polek TI. Correlation of ESR line-shape and conductivity in low-level Bi doped lanthanum manganites. The European Physical Journal Applied Physics. 2017;80(2):20701. doi:10.1051/epjap/2017170198

[30] Sambasiva Rao P, Subramanian S. Jahn-Teller tunneling in copper(II)-doped hexaimidazole zinc(II) dichloride tetrahydrate. Journal of Magnetic Resonance (1969). 1976;22(2):191-206. doi:10.1016/0022-2364(76)90294-8

[31] Kedzie RW, Kestigian M. PMR Determination of transition metal ion sites and multiplicity of rare-earth ion sites in $\mathrm{CaWO}_{4}$. Applied Physics Letters. 1963;3(5):86-7. doi:10.1063/1.1753880

[32] J. Smith and H.P.J. Wijn, Ferrites, John Wiley (1959) New York.

[33] Li L, Li G, Smith, RL, Inomata H. Microstructural Evolution and Magnetic Properties of $\mathrm{NiFe}_{2} \mathrm{O}_{4}$ Nanocrystals Dispersed in Amorphous Silica. Chemistry of Materials. 2000;12(12):3705-14. doi:10.1021/cm0004811

[34] Zwierzycki M. Transport Properties of Rippled Graphene. Acta Physica Polonica A. Institute of Physics, Polish Academy of Sciences; 2012;121(5-6):1246-9. doi:10.12693/aphyspola.121.1246

[35] Eaborn C. The chemistry of the copper and zinc triads. Journal of Organometallic Chemistry. 1995;490(1-2):C37. doi:10.1016/0022-328x(95)90299-t

[36] Gewirth AA, Cohen SL, Schugar HJ, Solomon EI. Spectroscopic and theoretical studies of the unusual EPR parameters of distorted tetrahedral cupric sites: correlations to x-ray spectral features of core levels. Inorganic Chemistry. 1987;26(7):1133-46. doi:10.1021/ic00254a032

[37] Attanasio D, Collamati I, Ercolani C. Complexing properties of $\alpha$-nitroketones. Complexes of nickel(II) and cobalt(II). J Chem Soc, Dalton Trans. 1972;(6):772-80. doi:10.1039/dt9720000772

[38] Krishan S. Strong Laser Plasma Coupling. Strongly Coupled Plasmas. 1978;547-56. doi:10.1007/978-1-4613-2868-1_17

[39] Procter IM, Hathaway BJ, Nicholls P. The electronic properties and stereochemistry of the copper(II) ion. Part I. Bis(ethylenediamine)copper(II) complexes. Journal of the Chemical Society A: Inorganic, Physical, Theoretical. 1968;1678. doi:10.1039/ j19680001678

[40] Tomlinson AAG, Hathaway BJ. The electronic properties and stereochemistry of the copper(II) ion. Part II. The monoamine adducts of bisethylenediaminecopper(II) complexes. Journal of the Chemical Society A: Inorganic, Physical, Theoretical. 1968;1685. doi:10.1039/j19680001685

[41] Bew MJ, Hathaway BJ, Fereday RJ. Electronic properties and stereochemistry of the copper(II) ion. Part VII. Mono(diethylenetriamine)copper(II) complexes. Journal of the Chemical Society, Dalton Transactions. 1972;(12):1229. doi:10.1039/dt9720001229

[42] Billing DE, Hathaway BJ, Nicholls P. Polarisations of the copper(II) and uranyl electronic spectra of meta-zeunerite single crystals. Journal of the Chemical Society A: Inorganic, Physical, Theoretical. 1969;316. doi:10.1039/j19690000316

[43] Fereday RJ, Hathaway BJ. The polarised single-crystal electronic spectra of bisdi(2-aminoethyl)-aminenickel(II) chloride monohydrate. Journal of the Chemical Society, Dalton Transactions. 1972;(2):197. doi:10.1039/dt9720000197

[44] Billing DE, Hathaway BJ. The crystal-field energy levels of dibarium copper(II) formate tetrahydrate and copper(II) formate tetrahydrate. Journal of the Chemical Society A: Inorganic, Physical, Theoretical. 1968;1516. doi:10.1039/j19680001516

[45] Mishra S, Kundu TK, Barick KC, Bahadur D, Chakravorty D. Preparation of nanocrystalline $\mathrm{MnFe}_{2} \mathrm{O}_{4}$ by doping with Ti4+ ions using solid-state reaction route. Journal of Magnetism and Magnetic Materials. 2006;307(2):222-6. doi:10.1016/j.jmmm.2006.04.005

\section{Open Access}

This article is licensed under a Creative Commons Attribution 4.0 International License.

(C) The Author(s) 2019 